\title{
Correction to: Clinical and radiological outcomes of unilateral biportal endoscopic lumbar interbody fusion (ULIF) compared with conventional posterior lumbar interbody fusion (PLIF): 1-year follow-up
}

\author{
Man-Kyu Park ${ }^{1} \cdot$ Soo-An Park ${ }^{2,3} \cdot$ Sang-Kyu Son ${ }^{1} \cdot$ Weon-Wook Park ${ }^{2} \cdot$ Seung-Hyun Choi $^{2}$
}

Published online: 24 June 2019

(C) Springer-Verlag GmbH Germany, part of Springer Nature 2019

Correction to: Neurosurgical Review

https://doi.org/10.1007/s10143-019-01114-3

The original publication of this article has incorrect presentation of one of the author names. Instead of Sangu-Kyu Son, it should have been Sang-Kyu Son.

The original article has been corrected.

Publisher's note Springer Nature remains neutral with regard to jurisdictional claims in published maps and institutional affiliations.

The online version of the original article can be found at https://doi.org/ 10.1007/s10143-019-01114-3

Soo-An Park

sooan.park@gmail.com

1 Department of Neurosurgery, Parkweonwook Hospital, Busan, South Korea

2 Department of Orthopaedic Surgery, Parkweonwook Hospital, 4, Gwangan-ro, Suyeong-gu, Busan 48298, South Korea

3 Department of Orthopaedic Surgery, Chung General Hospital, 76, Sujeong-ro, Sujeong-gu, Seongnam-si, Gyeonggi-do 13316, South Korea 